\title{
A poética subversora de Max Martins
}

The subversive poetry of Max Martins

\author{
Amarílis TUPIASSÚ* \\ Universidade Federal do Pará (UFPA)
}

\begin{abstract}
RESUMO: Partindo de uma relação entre a carga visual das capas de H'era e $O$ risco subscrito e a poesia de Max Martins, o presente ensaio explora a noção de poema como espaço de pluralização de sentidos na radicalização da síntese poética maxiana, ancorando-se no estudo de imagens que percorrem a obra de Max Martins, desde o primeiro livro, $O$ estranho, de 1952, até 1992, como a da pedra, a da escavação e do oco. Aposta ainda na leitura de um propósito de ruptura com o sistema normativo da língua por meio do tratamento dado ao tempo, na escolha de recursos poéticos como o jogo de inversões interrogações e em sua articulação com as noções de memória e escrita.
\end{abstract}

PALAVRAS-CHAVE: Max Martins. Criação Poética. Tempo. Memória.

ABSTRACT: From the analysis of the cover of two books by Max Martins - H'era and $O$ risco subscrito - this text explores the notion of the poem as the realm where the poet can manipulate the multiplicity of meanings in the most synthetic form. It studies the use of images that repeatedly appear in his poems, from the first book, in 1952, through the last, in 1992, such as the image of the stone, the act of excavating and the hollow. It bets on the ideia that his poetry aims at breaking up with the regulatory system of the language by his personal notion of time, the use of poetic devices such as inversions and repetitive questioning, and its articulation with the notions of memory and writing.

KEYWORDS: Max Martins. Poetic Creation. Time. Memory

Recebido em 25 de novembro de 2016. Aprovado em 28 de novembro de 2016.

\footnotetext{
* Amaríllis Tupiassú é professora da Universidade Federal do Pará e da Universidade da Amazônia (UNAMA), Belém, PA. Doutora em Teoria Literária pela Universidade Federal do Rio de Janeiro. E-mail: netunovillas@orm.com.br.
} 
No cômputo geral de quanto compôs na ordem do estético, o poeta Max Martins apodera-se da linguagem em todas as modalidades. E engendra-a, reengendra, ata, desata-a, cria formas, inventa notações, à primeira vista, insólitas, embaralha-as em ritmos inusitados, age com destemor frente à palavra, o poeta cheio de inconformismo, para edificar uma obra poética subversora que interroga o tempo, o ser, o transiente, o eu que grafa a frase, o leitor que a reedifica a beleza poética e se acumplicia do criador na contemplação da vida que lateja em uma obra de permanente beleza. Assim se dá a ventura da obra de Max Martins.

Num dia, em 1971, o artista plástico Waldir Saruby de Medeiros idealizava arte para a capa do livro H'era (Rio de Janeiro - GB: SAGA) que Max Martins daria a público naquele ano. Waldir, muito sensível, olhar arguto, atilado, sentidos tensionados a abrir o melhor traço ao merecimento do livro, concebeu uma tela. Ali reproduziu uma teia, um emaranhado complicado de pequeníssimas artérias tortuosas, não obstante os sulcos se abrirem também em retas que terminam por retorcer-se em uma totalidade harmônica. Não importa se em curvas sibilinas e sinuosas ou em horizontalidade, em sucessividade. De qualquer modo, os traços destacam uma disposição labiríntica, um torvelinho de sendas, sem início, meio e fim, a marcar o redemoinho de riscos em flanérie, como a flutuar levezas no espaço branco.

Este verbo flutuar emprego-o aqui porque surgiu de pronto quando examinava o enxurro de sugestões advindas do novelo desenrolado ou emaranhado de filamentos, a ilustração da capa, como que a deslocar-se no ar, solto, fecundando os vácuos feitos de branco (ou lacunas?) sobre o qual (branco) se engastam as pequeníssimas trilhas rumo à lombada do tomo. Waldir Saruby, a ideia deve ter partido dele, não satisfeito em grafitar o torvelinho a partir da fartura significativa do titulo $H$ 'era (subtraída do campo da capa, talvez para furtar-se à redundância) dispôs as linhas em trancelim volumoso, parecendo irromper dos nomes do livro e do poeta Max Martins, estas as únicas palavras da capa, das quais se distendem os trilhos, o caminho, a vereda de finíssimos fios, estes tão delicados - e quem sabe - perigosamente aproximados, tensionando o delineado profuso, os riscos 
muitos e muito próximos, que fluem em direção ao espaço restrito onde se articulam, apesar de cada um por si, a garantir seu próprio entrançado.

Exímio leitor de Max Martins, Waldir Saruby ofertou naquele mapa-capa, sem demarcações de limites, um ícone da geografia por onde se pode vislumbrar, por exemplo, o poema "Na estrada" do livro Caminho de Marahu (1983)

$$
\begin{aligned}
& \text { Botas } \\
& \text { que me fizeram a infância } \\
& \text { tortas } \\
& \text { e para sempre a vida } \\
& \text { rotas }
\end{aligned}
$$

Reservemos um tempo ao poema. Apesar de sua brevidade, o texto se estende dado ao duplo ou até triplo sentido das palavras nele empregadas. O redemoinho de sentido já sugere o riscado de Waldir. É como se as linhas tocassem os versos, como se se espalhassem soltos flutuantes em muitos significados, que tilintam e entrecruzam-se, de tal maneira que nas entrelinhas se erigem mais discurso.

Em outras palavras, numa espécie de visão contra o sol ressaltam-se os avessos, os entremeios em que outras linhas poemáticas também se alojam em acúmulo num mesmo nome.

Diante desse acúmulo, cabe ao leitor a tarefa de descolar essas linhas que se formatam uma por dentro da outra, a lembrar a maranha de traços desenhada por Saruby na capa do livro. Por isso mencionei o ícone, aquilo que se expressa com o uso da reprodução do mesmo, no modo de reflexão espelhal, o que ocorre entre o desenho da capa e os poemas.

Para fazer aflorar essa riqueza verbal, cabe ao leitor revolver os sentidos das palavras que compõem o poema. Desconfiar da aparente banalidade das palavras usadas, acionar o uso plurissêmico, ou de a mesma palavra acondicionar vários significados, ter em mente que uma palavra tem vários sentidos, buscar esses sentidos, interpretá-los no que têm de sutil, tão sutis as palavras que, se o leitor não estiver de sobreaviso, pode deixar passar a carga plural, de metáfora, de insinuações, acumulada no texto. 
Os poemas de Max Martins têm por selo, por timbre, o emprego de palavras exploradas, enquanto espaço de vários sentidos, os quais devem ser buscados, todos, como atestado de viço, de vigor poético. O poema não conta formalmente uma história, mas conta, uma história embutida nos implícitos dos versos. Cabe cavar, ir à profundidade, à interioridade, à verticalidade verbal, que sempre há, e recuperar um só quadro e pluralíssimos dizeres, o que nem sempre se dispõe às claras.

Vejamos o substantivo "botas" sem indicadores de propriedade. De quem são as botas? São do eu, o sujeito poemático que vive o caso do poema ou de outrem? Como se sabe, botas é uma palavra que pode indicar autoridade, quero dizer, é uma palavra que indica o poder de mandar, palavra que denota força, poder, porque quem usa bota não é uma donzela a dançar uma valsa de quinze anos. O texto não lança mão de calçado em senso absoluto, qualquer calçado. Lança mão de um calçado específico, de botas, de uso particular interligado a ações sobretudo castrenses, palavra de guerra, pode ser, a atividades de chãos pesados, de soldado a marchar. Mas quem calça essas botas, cujas pisadas entortam a infância?

Por outro lado, essas "botas" rimam com o substantivo "rotas". Veja-se que, em língua portuguesa anterior, num português passado, podia-se diferençar rotas/rôtas, esta última com o acento circunflexo diferencial para significar o que está rompido, rasgado. Rota era e é caminho. Hoje, as duas palavras podem ser caminho e algo rasgado/rompido. Não existe uma mais correta leitura da letra "o". Já não existe o acento circunflexo com uso de acento diferencial em língua portuguesa. Por outro lado, é obrigação do leitor ler todos os sentidos que um escrito, poema ou qualquer outro texto ponha em circulação. Isso nos obriga a ler no poema rotas (caminhos) e também rotas com a acepção de rompidas, rasgadas que, na anterioridade se escrevia rôtas. E o texto é invadido por algo rompido, rasgado, o que quer dizer ferida, do que se pode interpretar no poema um caminho, uma rota de vida infantil já com a dureza da bota e com rotas rompidas. Esses sentidos estão latentes. Ao leitor desavisado, o poema é uma bobagem. 
Atente-se que o eu, sujeito do poema desenrola então um ciclo vital, a rota/rôta que dota o poema de uma sutil carga de pessimismo, essa uma das tônicas do poemário de Max Martins.

Observe-se também que essas botas não só são calçadas por alguém, num período determinado, fechado. Calçam a infância "e para sempre a vida", de que o poema vem à recepção com o resumo de vida expresso num poema assim descarnado, assim tão resumido, com poucas palavras, sintético, feito de pouca substância verbal e que, na falsa carência verbal, inscreve múltiplos sentidos, mais especificamente três rimas: "botas", “tortas", "rotas". É preciso ir adiante na arqueologia semântica. "Botas", "tortas", "rotas", rôtas estas simples palavras desdobráveis em três versos de significado à parte, se revertermos o substantivo botas, no verbo botar, o que é plenamente possível, em uma só pessoa gramatical, "tu botas", a segunda pessoa do verbo botar, pôr. Mas botar o quê? O verbo botar, na qualidade de verbo objetivo direto precisa de complemento. Na falta de seu complemento direto, esse verbo se amplifica e, à pergunta: botas o quê?, a resposta pode ser à escolha de quem pergunta. Como o poema dissemina sentidos negativos, claro que o leitor há de completar o verbo com um complemento pessimista, porque o poema dissemina sentidos negativos.

$\mathrm{Na}$ sequência desse raciocínio, a partir das transformações verbais, poder-se-ia ainda ler, nesse Max, a frase "Tu botas [na vida] rotas tortas e rôtas".

Tais desdobramentos, advindos, conscientes ou não, pouco importa, da lavra criadora do poeta, incita a leitura plural a que deve estar atento outro leitor e concordar ou não com o meu ponto de vista.

Max Martins era um encantador de palavras. Detinha sobre elas um conhecimento lindo e alarmantemente extenso, preciso, precioso. Amava-as com ternura e sofreguidão. Andava sempre com um caderninho e anotava palavras a seu ver bonitas e incomuns. Dizia que as palavras têm vida como os seres de sangue quente ou frio, que namoram, se amam, casam; se muito usadas, gastam-se, têm cansaços. Não há dúvida de que a simplicidade do poema acima foi fruto de muito trabalho, porque a brota do complicado é fácil. Difícil e custoso é dar vida ao simples. 
A arte da capa, as linhas finíssimas e intrincadas da tela externa (da capa) de Waldir Saruby já anunciam ou espelham o conteúdo dos poemas que se desenrolam no virar das folhas internas, num jogo em que o visual se conjuga com o linguístico. Saruby, como amigo e finíssimo leitor de Max, sabia do poder que o poeta detinha sobre o discurso. Foi ato buscado o emaranhado organizado da capa, prelúdio da carnadura frasal dos poemas.

Outro artista plástico, Emmanuel Nassar, fez a capa de $O$ risco subscrito (Belém: MITOGRAPH, 1980) coletânea de poemas editada em 1980. E uma cartografia anterior tingiu-se à portada do livro, um tecido compacto de linhas sutis, sem começo nem fỉm, induzindo o leitor a ver os escaninhos quase imperceptíveis, quais veios de uma palma de mão, que se disformando, sonegam à recepção, ao leitor, uma visão verbal rigidamente demarcada, precisa, unissêmica, indiscutível. É preciso não esquecer o duplo sentido da palavra "risco", a acepção que assinala o gráfico, e a que indica risco a semântico. Este é o risco que é perigo, que é ameaça de queda possível, $O$ risco subscrito, grafado, sim, com fervor, com fervura também nos significados que correm no explícito das palavras, assim como no implícito, nas entrelinhas, nas sublinhas, no subtexto.

Emmanuel Nassar, tanto quanto Waldir Saruby, resolvem-se à feitura da representação icônica, a imagem, a representação em que o sentido expresso está na pintura da própria imagem, desejada como espelho que reflete o mesmo, reflete o redemoinho de vozes dos poemas. Uma fotografia, por exemplo, basta olhar a face e, se é alguém conhecido, sabe-se logo de quem se trata. É o ícone. O título $O$ risco subscrito exerce, na área visual da capa, a primeira atração à abertura das páginas, porque a capa já diz de uma constância do texto maxiano. Ver a capa incita de imediato a pensar na vida em suas linhas complicadas, dificilmente em linhas retas no mundo, incita a pensar nas errâncias, nas andanças, a vida em sublime ou diabólica acrobacia, em concerto de belezas e feiuras, essa a matéria do poeta, o cerne de sua poesia.

Muito difícil, suprassumamente difícil, dizer a vida, representá-la, experimentar e intentar a agudeza do signo, da palavra, um encargo a que Max Martins se voltava, como a um quase impossível mister - o poeta afirmava - porque a ação escrita é quase sempre inconclusa, quando quer vibrar os timbres mais agudos da vida e representá-la nos 
territórios da poesia que permanece, a arte poética que atravessa os tempos, a palavra sempre moderna, porque sempre viva, aquela que sempre tem o que dizer aos humanos de todas as eras porque sempre cheia e atual.

De modo geral, as duas capas agem como insígnias dos transes, dos trâmites e frêmitos, das conturbações e das graças, da ascensão e queda, dos registros que se ativam no universo poético de Max Martins, suas linhas abertas a interrogações, às respostas quase sempre relegadas ao branco do irrespondível ou ao denso cinza das respostas provisórias.

A mais antiga e mais vibrátil cadência de força ou tônus estético (emprego aqui esta palavra em seu sentido fisiológico, de contração muscular leve e contínua) impressa por Max Martins em sua produção artística advém muito cedo como fruto de insaciáveis sedes: a de dotar-se de ciência, de saber sobre a palavra. Daí a poesia em que persiste a luta por alcançar os picos, a luta por ascender à perfeita dicção literária.

No seu próprio texto impõem-se as metáforas da seta, do voo, da ave. Dessa metaforização advém o combate por vencer a queda, por deter ou reverter o percurso em queda. Nasce a imagem da ave, do voo, qualquer um. E logo se estabelece a reiteração do movimento de descida/queda/ascensão na obra poética, a escavação em busca de desvendar os porquês, não importa a dureza de que ressaem movimentos de inquietação, de desassossego; nas falhas, espécies não sobrevivem em paz no magma mais um pouco ao fundo, à ida ao oco, ao profundo de existir.

O poema “Enterro dos Ossos” (MARTINS, 1992, p. 176) é abonação de ascensão e queda, de ida à culminância e aos abissos, onde se esconde ou repousa a verdade de serestar-transformar-se-metamorfosear-se-destinar-se ao pleno e ao precário, o ser imerso em fim e nada.

Mas os poemas denotam e conotam outra sede, a que se espraia aos confins do sonho, do desejo, também de ascender à frase poética ideal, ao belo mais inteiro, à palavra mobilizada como desejo de fruição do estado pleno e da anulação do precário e da falta.

Aqui se mencione a associação da poética maxiana com a figuração do túnel de Júlio Cortázar. Max enfatiza uma espécie de desmonte e remontagem, a pródiga "agressão 
contra a linguagem literária, essa destruição de formas tradicionais [que] tem a característica própria de um túnel; destrói para construir” (CORTÁZAR, 1998, p. 49).

A palavra de Max nunca se despojará dos propósitos maiores de escavar a língua dos cimos aos ocos do verbo e arriscar-se a grafar o resvalo, a queda, o inconcluso. É o que expressa o poema "Narciso"

Esta atitude de pôr os olhos além das flores

E do resto das mulheres,

Pensamentos sobrepujando céus,

Deves compreender.

Amo-me.

Não que eu tenha muitas gravatas

Nem mesmo porque negros sejam os meus olhos!

Este amor sem eco.

No vazio, deves compreender.

(O estranho, 1952)

O Max (que cava no vazio do túnel de Cortázar para construir-se) perdurará, desde os poemas de 1952. São as primeiras produções, logo, das primeiras criações até os poemas de 1992, como “A fera” (MARTINS, 1992). Nesse poema a fala, a ação elocutiva se funda e fecunda em avanços e retroações. No ir e vir contínuo, massacrante, muito a fim de domar a escrita. E se instaure e vibre a fala estética, à força de muito fazer e refazer o risco, o subscrito, ao ansiado encontro da têmpera. Nesse encontro, o poema, o poético há de imporse lúcido e irrefutável, o belo do dizer que, ao instituir-se como beleza, abranja os largos de existir.

Sim, e os poemas o dizem, só o apuramento do discurso pode aplacar a vontade de ir à essência, a fome de devassar os leitos e as margens onde, com amplitude, conjuga-se a poesia e/com o triunfo sobre a fera-palavra. Urge sempre caçar e domar o verbo atrelado ao ser, aquele que grafa e o que é grafado, no visto, no verso claro e explícito e no latente, no invisível. Vejamos o poema "Entrelinha" (60/ 85, 1985): 


$$
\begin{aligned}
& \text { Caço a palavra caço-me } \\
& \text { na palavra ato-me } \\
& \text { à palavra } \\
& \text { E me desato suniato-me sumo } \\
& \text { na sombra do silêncio da palavra? }
\end{aligned}
$$

\section{(Marahu, março 85)}

Como se vê, é impossível dissociar da poesia de Max Martins a condição de texto fadado ao triunfante, ao genesíaco, à língua instauradora de uma realidade outra sobre quê o demiurgo (segundo Platão aquele que cria o universo, organizando a matéria preexistente) impõe o Fiat lux.

No curso, no transcurso, na lalação inaugural, na silabação paciente dessa obra, aflora a voz demiúrgica, quando o dom divinatório do criador expulsa das sombras do impronunciável os caudais que manam, que volteiam, o ser e estar no mundo e se derramam em desejo pelas trilhas caudalosas de um discurso bem-posto e composto como morada poética, alongado das demandas práticas, estas as demandas automatizadas de dizer. Para tanto bastaria a menção ao furor das horas, viver apenas e verbalizar as horas vividas, dizer apenas o prático-vivencial, o poeta alheio às interrogações, às dúvidas, às exasperações face ao não-saber, ao emudecimento.

Max, desde os primeiros textos executa esse concerto, essa orquestração poética. Ele nunca se contentou com o discurso prático-social. Em sua casa circulavam livros. Max tinha ciência e consumia outras palavras, não apenas as palavras de levar a vida à frente. Muito cedo se enfronha com a poesia. Com aquela de acesso mais fácil por este Norte, a poesia da tradição e da convenção academicista. Quando se dá conta da literatura do final da década de 30, século XX, dá-se a explosão.

Em conversa, entrevista, quando do registro de si e seus feitos, no Museu da Imagem e do Som/PA, afirmou terem se perdidos seus primeiros poemas, segundo ele, de 
estruturação parnasiana. Esses poemas sumiram, com exceção de um trecho de "Soneto", cujo primeiro verso alude aos "Ventos do mar em búzio azul", do livro O estranho. Os de fatura já modernista, segundo a denominação do poeta, associam-se à tarefa também de devassar o discurso vertido à engorda poética; os que se impõem como trabalho de acurar a visão, o olho agudo de ver para além da pele dos seres, para além do superficial, a voz poética levada a estiletar a carne e escavar a vida até o âmago, o estilete devassador a escrever aquilo que ressai dessa funda visão, o intento de alcançar os páramos secretos, o refúgio quase blindado de ser, os centros aonde irrompe e mana a verdade inatingível, talvez só entrevista entre brumas, quais os cortinados da caverna platônica.

Para tanto, faz-se necessário retroagir, atacar os aquéns e aléns, fincar pés no in, no intro. $\mathrm{O}$ poeta há de mobilizar um aparato verbal espicaçado, amolada à lâmina em brasa, a consciência e o verbo em fogo, a esgrimir, a correr o percurso vital, passado, presente, futuro, uma temporalidade una, solidária, para que se articule à luz da página a palavra capaz de atuar como suplência, como maneira de driblar as faltas da parca e embaçada visão humana.

Benedito Nunes, na "orelha" do livro $O$ estranho, é enfático quando fecha em torno do homem Max Martins uma circunferência dentro de que só se imprimem as pegadas da poesia:

Se bem que tenha carteira profissional onde, talvez, por toda a vida, seja, apenas, um nome dentro da vasta e atribulada classe dos comerciários, Max exerce realmente a profissão da poesia e dela não se afasta nem mesmo quando os balancetes obrigam-no a curvar-se sobre a mesa do escritório. Essa circunstância é mais importante do que parece à primeira vista, pois que a sua poesia reflete profundas ligações com a vida cotidiana, da qual ele extrai uma boa parte dos elementos que fertilizam os versos rebeldes de Estranho, que chegam a ser, por vezes, impuros, mas nunca artificiais, vazios e desprovidos desse conteúdo humano que dá a medida ao sentimento do mundo e a toda poesia verdadeiramente autêntica. (NUNES, 1952, “Apresentação" do livro O estranho). 
É nesse tom que a produção de Max alcança a concretude da página. É o caso, por exemplo, dos versos de "Outro sim" (Marahu poemas, 1991), conclamando à outra ida, à palavra vivificadora, o único pilar possível à construção, à sustentação de vida e amor:

Para que não se vá a vida ainda e a amada volte

pede à palavra outra palavra outra sob palavra

Algumas imagens reiteradas percorrem a obra de Max Martins. A já mencionada pedra, a dureza da pedra e a consequente escavação, a que se possa desprender do oco, da cava, o vero de ser:

\section{C'eu \\ - eco do oco - \\ C'ego}

(Caminho de Marahu, 1983)

Frente à verdade encravada em tudo, a verdade vedada à compreensão quotidiana, cabe ao olho, em vigília contra a morte, a lucidez de intentar sempre a perfuração para que desaguem os sentidos, os mistérios. O poema "Saber" (inédito), em sua brevidade, incita à teimosia, única arma a acalmar o descontentamento, única droga a sedar a inconformação. Nesse afã, ecoa esta poesia impaciente, de timbre irritadiço, que ascende à escrita qual divisa, qual emblema bordado no escudo do lutador: "Todas as portas estão abertas/ ou não há portas".

A verdadeira escola de Max Martins foi a domação, a adoração, a consumição da palavra:

Eu começo na poesia entre os 14 e 15 anos. Uma poesia nos moldes de então: parnasiana, bem feita, de acordo com o figurino acadêmico e tradicional. Depois eu descobri o Modernismo. Eu devo ao Francisco/ Chico [Francisco Paulo do Nascimento Mendes]a descoberta do 
Modernismo. (entrevista ao jornalista Tito Barata, de 24 a 31 de julho, 2000).

Nesta mesma entrevista, se estabelece o grau da autoexigência poética de Max que reduz seus primeiros poemas modernistas ( $O$ estranho, 1952) a simples "anotações líricas". Esses textos tomados por ele como meros exercícios num primeiro estágio do aprendiz de poeta foram elaborados sob o peso da timidez (confessada em depoimento ao Museu da Imagem e do Som, em 25 de setembro de 1996 - Fundação Tancredo Neves) e da inveja:

Eu tinha inveja dos garotos reunidos na porta da minha casa, na adolescência, que improvisavam peças de teatro na rua. E esses garotos se entrosavam bem com as garotas das redondezas. Eu ficava com inveja, me achando incompetente para representar. Então eu descobri um poema, dentre os recortes da minha mãe, de um poeta paraense [Rocha Júnior], meu tio, irmão dela, que era dedicado à mãe dele. Logo também fiz um, dedicado à minha mãe, sem metrificação, nem nada. E por aí fui...

Mesmo vistos como tenteios de menoridade, uma constante dessas produções é já a insubmissão, a subversão, a recorrência contra o tempo, compreendido como móvel da desagregação, da falta, da perda. Ainda que seja reiteração em toda a obra, nas primeiras poesias ponteia a fala sem o vigor e um mais visível delineamento assumido depois. Esse tempo corrosivo, cáustico, abrasivo, triturador já se abate sobre o "estranho" e seu universo, uma temporalidade a fluir e a puir os tecidos da vida e a matéria reminiscente.

"Do poema da infância" exemplifica essa poesia da primeira hora cuja linha de força será recorrência, dali em diante, aprofundada, transformada na tessitura de uma obra obsessivamente posta a atingir a culminância do verbo cada vez mais afinado e aguçado, pronto à elocução das essências.

Vale ler com mais vagar o primeiro poema do primeiro livro datado de 1952, reeditado em 1992:

\section{Do poema da infância}

\section{1}

Que cabelos prende o laço róseo

flutuando entre nuvens? 
(A menina do laçarote é loura, morena ou rica?)

Em que mala estará o Pierrot cor de jerimum?

Velocípede - revolução - Felisberto de Carvalho -

Angelita dos quadris morenos e peito em embrião.

Não me vejo menino sem Marieta

(O estranho, 1952)

Já o título evidencia o emprego do verbo sorrateiro, sibilino, potencializando a ambiguidade capaz de pôr em circulação a palavra em seus vários significados intercorrentes. Jamais a palavra, o revolver com a "pá escavadora" do poeta, limita-se aos sentidos gastos, maquinais da fala somente comunicativa e prática. O título já expressa a subversão vocabular; já enuncia os limites da memória. Não se trata de poema da infância, mas de partes, nesgas, pedaços, fiapos, uma vez que o título é: "Do poema da infância". A contração inicial (de+o="Do") evidencia que se trata só de um pedaço tirado da infância. Mas as palavras estão como se embaralhadas. Houve um poema da infância, a ponto de e dizer Do poema da infância? Ou da infância se separou uma parte e dela se fez um poema? Não importa. Importa marcar o dúbio instalado já no título.

Desde suas primeiras criações, Max Martins aciona esses "riscos subscritos", move sentidos subentendidos que, se foram abertos nos versos, devem ser lidos.

De qualquer maneira, há diferença entre "O poema da infância", "Um poema da infância" e "Do poema da infância" redutível a "Algo restante do poema da infância", frase em que se pode entender que as palavras poema e infância se equivalem. Dessa infância restam poucos vestígios, resta um laço róseo fadado a promover apenas um enlace residual, fímbrias de claridade lançadas numa zona de desagregações interpessoais reinstaurada pela poesia.

Na sequência dos versos, observe-se o poder da sutileza. Max grafou o primeiro verso invertendo a ordem direta das palavras. O único elemento a evidenciar um sentido indireto à frase é a concordância gramatical. Vejamos: “Que cabelos prende o laço róseo?”, “Que laço róseo prende cabelos?”. A inversão das palavras na interrogativa desagrega a frase. É uma inversão que imprime ao verso outro significado e lhe confere estranhamento. 
As palavras livres, soltas convidam à leitura de significado amplo, de vez que desengastadas da ordem direta do discurso.

Assim, laço? Elos interindividuais? Róseo? A simbologia das cores assinala a placidez da jovem infanta? Prende? O que se prende a quê? Cabelos? Fios de fragilidade? De imediato, desprende-se dessas palavras um sentido objetivo. Logo se prendem a estes "cabelos" as sobras, os restos de um corpo inteiro de menina. Rápido se anula o sentido dicionarizado, colando-se ao verso outro significado, o do enlaçamento precário, dada a fragilidade de cabelo, que assume a ação de atar, conforme leitura possível das palavras se rearrumarmos a frase. Apenas a metáfora pode investir em cabelos a resistência de prender, metáfora que se intensifica quando o "laço róseo" é levado de um espaço histórico preciso, impossível de ser reconstruído nas malhas da verdade, para flutuar, entre nuvens, não do mundo objetivo, mas de uma realidade imaginada, rememorizada, substituta, persistente na memória, na poesia.

Veja-se o jogo de interrogações. Que cabelos prende o laço o laço cor de rosa? Talvez seja plausível afirmar que a palavra cabelos indica tanto para a cabeça/memória do sujeito que evoca, quanto para a lembrança residual da menina de quem se tenta a reinstituição, vencido o tempo histórico, vencidas as horas da existência real. O verso "Que cabelos prende o laço róseo?" alimenta o eixo significativo em que "cabelos" é tomado como algo que cresce para fora a recobrir, obscurecer o interior em que se situa o órgão, o cérebro, que retém, guarda as imagens, o resto que ficou, se sobrevier a arte reinstauradora.

Outro aspecto que chama atenção neste primeiro poema são as projeções supostamente autobiográficas, bem como a discursividade e o realismo, falso, logo se verá, pois uma leitura mais pausada revelará um modo delicadíssimo de desdizer, de esvaziar os traços arraigados nos ideais estéticos fundados na rígida apreensão e reprodução objetiva do real. Esse esvaziamento resulta do emprego inusual, inusitado das palavras e do tratamento dado ao tempo, aliás, o mesmo tempo camoniano:

O tempo acaba o ano, o mês, a hora

A força, a arte, a manha, a fortaleza

O tempo acaba a fama e a riqueza

O tempo, o mesmo tempo de si chora [...]. 
Esse é o tempo reiterado às claras, nas sublinhas de Max, o tempo que mata, que suprime, o poder que se esbate sobre a memória, sobre o nítido evocar, o tempo-fim:

\author{
o tempo \\ em nós \\ separando o tempo \\ em nós \\ o pão separando o tempo \\ em nós \\ corta o pão separando o tempo \\ em nós \\ a faca
}

(Caminho de Marahu, 1983)

No poema "Tempo" é impossível deixar de lado o evidente e repetido pronome "nós", em nós, que agressivamente, devido à repetição, afirma igualmente o substantivo plural "nós", que significa também laço, amarrado, intriga, enredo, embaraço, as laçadas, a rigor, os nós que nos prendem à existência, que a paralisam e que separam mesmo, os fios em nó à volta de nós, só mesmo a peso de faca e olhe lá, quando os nós se cortam à faca.

Voltar ao passado, desejar ressuscitar as imagens retidas na memória vem a ser o esvaziamento da verdade ou a recuperação da verdade parcial ou da verdade possível. Neste ponto, vale vincular Max com uma conjugação de vozes pendidas no abismo em que se espelha a disputa entre o efêmero e o desejo de perenização. Lembrar, rememorizar passa a significar tatear entre resíduos, perder o centro, deparar o sumiço da imagem de traços definidores, concluir sobre em que medida o bico de pena cede vez ao sombreado do sujeito malmente visto. Recompor o conteúdo da memória consegue apenas configurar o lacunar ou a mancha gráfica despojada do lineamento fundo-forma (a memória se pondo num paralelo às dissoluções impressionistas). Sim, porque rememorar incluirá sempre o entrançado da imaginação, o lusco-fusco, a algaravia, a silhueta em movimentos vãos, os 
traços soltos, o brumoso, os ecos, o relampejo fecundante da sobra, do resíduo que a palavra em sua ordenação estética ativará em conformação vicária, substitutiva.

Desde seu primeiro livro são postas as mesmas sementes a germinar, as sementes que irrigam os intentos iniciados oficialmente em 1952.

Max sabe que a poesia não prescinde da linguagem em todos os seus níveis e graus, em todos os seus aspectos e modalidades. Frente às várias matrizes da fala, ele jamais se posta com indiferença ou autossuficiências. Ele tem ciência plena de que poeta, o inventor há de apascentar o verbo, ciente de que o elemento expressivo do discurso estético é de difícil extração e que só a poesia dobra a linguagem em todos os seus possíveis, pacientemente, ingentemente.

Max vai acolhendo tudo, os particulares e os universais linguísticos, para que, de posse desse tesouro, possa firmar aliança com outras formas de significar. Sua poesia mantém associações com as sonoridades do canto, com a dança, visão, audição, com o enlace, com o casamento (Max é quem o diz) entre termos linguísticos, com as palavras em perfeita conjunção, com as imagens em gesto cinematográfico, com os nós em nos feito risco desdobrado na folha, a lembrar as garrettianas Folhas caídas.

A discursividade altamente elaborada, o verso solto, uma simples frase, um traço, um galho, um talo da árvore-vida, uma contorção lírica, ou seja, o verso dobrado a toda flexibilidade, esta é a palavra de Max em busca de harmonias novas. Tudo vale aos seus gestos verbais no jeito do que vier eu traço, seja que espécie verbal. O verso minimalista, quase um arfar de desejos, o verso das impaciências, o verso chateação, o desaforado, irritadiço, o poema inteiramente visual, as flexões paradoxais nos rastros de que são tecidos os seus koans, lição budista de expressão non-sense transmitida ao crente para induzi-lo à contemplação. O deixar correr as horas ao estilo Lao-Tzu ou a modo Alberto Caeiro e, tantas vezes, o versejar maxiano institui-se ao largo de contemplar, apenas, os nós embaraçados e naturais de ser. Isso pode se dar quando o poema, em fusão com o chiste, com o engraçado, com o gracejo, com o humor (“O nada é um balão sem pele”, "A pá nas minhas mãos vazias") tende a despir as palavras de todos os seus significados lógicos, sobrelevando o valor relativo do discurso à tentativa de, ante o impossível de alcançar o oco 
da vida, lá onde se aninha o conhecimento absoluto do ser, das coisas do mundo, dispor-se a um estado de total contemplação. É o desejo inscrito no poema "Koan":

A pá nas minhas mãos vazias*

\author{
Não a pá de ser \\ mas a de estar, sendo pá \\ lavra no vento \\ nuvem-poema \\ arco \\ busco-te-em-mim dentro dum lago \\ $\max$ \\ eKOÃdo** \\ e a face ex-garça-se verdemusgo \\ muda $[\ldots]$
}

(H'era, 1971)

Sua obra está imersa na História, no temporal que se configura em tons biográficos (de si e seus interlocutores), desde que a historicidade do biografismo se transfigure à força da intemporalidade das perspectivas alargadas, até longe, muito longe, aquém e além, passado, presente, futuro, ao alcance do Homem genérico, intemporal.

Mas, a propósito, o compromisso mais com o futuro que com o passado, o vezo à experimentação, até a desabusadada, amoral, imoral, o reótico, a sexualidade exposta, o que se poderia indicar como a despudorada palavra, porque tudo, absolutamente ao verbo é lícito, dizer, evocar, re(a)presentar, aquilo que as escavações da pá escavam, em explorações por todas as sintaxes e semânticas, por todas as formas e conteúdos, a palavra a inventar-se, a reinventar-se, feito o acima "eKOÃdo", a valentia de romper com o sistema de normas da língua, a linguagem, a fala maxiana invadindo pelo verso e reverso dos possíveis linguísticos, dos redutos do verso ideograma, da poesia imagem, o universo semiótico juntado ao bê-á-bá da frase-tradição, tudo no texto, quer poemático ou e prosaico, o risco avançando a possibilidades de significar jamais esgotadas. E tem mais: muitas 
vezes ele em Max escritura borda-se aborda ao vivo, passeando autorreferenciado pelas florestas de signo, ou melhor, de versos.

Mas o poema, desse modo, há de inscrever-se como cansaço, daí o poema-fadiga (de ser, estar, fazer), o poema-estafa, o poema inconcluso sempre, o poema em plena escavação, como Max deixa claro em "A Shan-hui”:

Isto não é um poema ainda

é só trabalho duro, muro

de pedra e nada - a pá

nas minhas mãos vazias

$(60 / 35,1985)$

Aliás, ao instituir um intérmino trabalho de intertextualização, ou seja, uma conversação entre textos, no global de sua obra, Max opera poemas fixado numa espécie de texto-torrente, de palavras líquidas, estas a escorrer incessantemente de uma página a outra em flagrante conversaria. Esse é o trabalho de acionar "a pá" a demolir "o muro" na fome por alcançar "o oco". O poema objeto, o poema coisa (o clímax da concretização contraposta ao koan, talvez o clímax da abstração, da especulação, reflexão), o poema abrigo da dissolução verbal, dissolução do indivíduo, a dissolvição de tudo, a intercorrência entre seres, entre reinos, espécies, gênero, número, grau.

Enfim, para Max Martins jamais a escritura da poesia se constitui como aceitação de um estatuto já posto, acatado, inquestionavelmente definido, estipulado. Seus ímpetos de negação, de recusa desacatam todos os estatuídos verbais e outros, éticos, estéticos. Ao mesmo tempo, seu grau de aceitação abrange, acata todos os saberes estabelecidos nas esferas do homem e da expressão, desde que o mote seja a instituição da beleza. Mesmo a beleza cimentada sobre o feio. Mas embaralhar todos os naipes e pagar para ver, arremessar-se às contracorrentes é a condição de seu jogo verbal. Estes são os seus trunfos ciosamente acalentados, desde 1952, ciosamente resguardados, ciosamente reembaralhados, renovados, para que se erga a cumeeira, a viga mestra, o vigor de sua lavra, sua abóbada, e 
se ateie a centelha, o viço (ou vício?) apaziguador, espicaçador, assegurado por sua poesia ao deleite de nós todos, ao deleite do próprio verso, do belo e denso verbo-beleza-fascínio.

\section{REFERÊNCIAS}

BARATA, Tito. http://www.belemdopara.com.br, de 24 a 31 de julho, 2000.

CORTÁZAR, Júlio. Obra crítica 1. Rio de Janeiro: Civilização Brasileira, 1998.

MARTINS, Max. O risco subscrito. Belém: Cejup, 1981.

. Caminhos de Marahu. Belém: Grafisa, 1983.

. 60/35. Belém: Cejup, 1985.

. Não para consolar. Belém: Cejup, 1992.

. Para ter onde ir. São Paulo: Massao Ohno, 1992.

NUNES, Benedito. H'era. In: Colóquio/Letras, n. 14, Lisboa,1973.

. "Max Martins, Mestres-Aprendiz” (prefácio). In: Max Martins. Não para consolar.

Belém: Cejup, 1992. 